\title{
Multi cases optimal reactive power dispatch using evolutionary programming
}

\author{
Rahmatul Hidayah Salimin ${ }^{1}$, Ismail Musirin ${ }^{2}$, Zulkiffli Abdul Hamid ${ }^{3}$, Afdallyna Fathiyah Harun ${ }^{4}$, \\ Saiful Izwan Suliman ${ }^{5}$, Hadi Suyono ${ }^{6}$, Rini Hasanah ${ }^{7}$ \\ 1,2,3,4,5 Faculty of Electrical Engineering, Universiti Teknologi MARA, Malaysia \\ ${ }^{6,7}$ Department of Electrical Engineering, Brawijaya University, Indonesia
}

\begin{tabular}{l}
\hline Article Info \\
\hline Article history: \\
Received Jun 10, 2019 \\
Revised Aug 13, 2019 \\
Accepted Aug 27, 2019 \\
\hline
\end{tabular}

Keywords:

Evolutionary programming

Loss minimization

Multi cases ORPD

\begin{abstract}
Evolutionary Programming (EP) is one of many types in Evolutionary Computation (EC) that used for optimization process. EP technique is used to find the optimal reactive power dispatch (ORPD) since it is one of the accessible options schemes that can be used on the system as a reactive power support. Sometimes, it is not necessary to operate all generators in order to perform ORPD to in achieve the objectives. Also, increment of reactive power load to the system will cause voltage decomposes with the increase in transmission loss in the system. Therefore, the proposed method decides the best grouping of generators that should be operated in system by bearing in mind the transmission loss reduction. ORPD will be used to minimize the transmission loss as well the increasing reactive power loading. This method conducted on IEEE 30-bus Test System with multi cases scenario. The best combination of operating generators determined and the transmission loss after optimization is smaller compared to the transmission loss before optimization resulted.
\end{abstract}

Copyright $@ 2020$ Institute of Advanced Engineering and Science. All rights reserved.

\section{Corresponding Author:}

Rahmatul Hidayah Salimin,

Faculty of Electrical Engineering,

Universiti Teknologi MARA,

40450 Shah Alam, Selangor, Malaysia.

Email: rhidayah@uitm.edu.my

\section{INTRODUCTION}

Power system is a composite network utilized for creating and transmitting electric power [1]. It needs a requirement to maintain the voltage stability in order to make the operation smoothly run. In power system operation, the power loading is not always fixed and usually it is increasing according to the demand. Along the increment of load demand, the voltage will slowly decrease with the increasing transmission loss in the power system. The greater part of the load demand included reactive power impacts because of changes in burden like motor installing, transformers and generator blackouts as opposed to the real power effect [2]. It can lead to insecure power system operation condition since the power system is required to work with utilization of minimal resources giving greatest security and reliability [1]. In order to avoid this problem, a solution should be considered to sustain the increment of reactive power loading and thus the transmission loss will be minimized as well the maximized voltage deviation. Towards settling this problem, it is a need to manage the reactive power resources in power which can be solved using the ORPD.

ORPD has a role that very significant in power system in order to ensure the economy, security and stability of a power system in secure condition. The main objective of the ORPD is to minimize the system real power loss [3]. Even ORPD is well known for transmission loss minimization, it also can used in appropriate scheduling of reactive power and its dispatch in the system [4]. Scheduling of reactive generators by determining the best combination operating system is suitable for decision making tool in order to use 
certain generator in minimising the transmission losses and maximising the voltage deviation. ORPD is originally a sub-issue of optimal power flow (OPF) estimations. It has been defined as a non-linear, multi-uncertainly, multi-constraint, multi-minimum and multi-objective optimization [5]. OPF was first introduced by Dommel and Tinney and developed by Carpentier in 1970s [6]. ORPD is a reactive power support through existing generator bus, synchronous condenser, capacitors, static compensators and tap charging transformer. This problem denotes optimal settings of control variables to minimize a certain object while satisfying equality and inequality constraints [7].

Numerous classical methods with excellent convergence characteristic have been developed and applied to solve ORPD problem in the past decades, such as Interior Point Method (IPM), Linear Programming (LP) and Quadratic Programming (QP). These methods also can be as conventional optimization techniques or mathematical optimization techniques. However, there exist some limitations and challenges for these methods to handle non-differentiable objectives functions and discrete variables in ORPD. LP method requires that the objectives function and constraints have linear relationship, which may lead to loss of accuracy [1]. Besides that, the Gradient and Newton methods which also the methods of mathematical optimization techniques suffer from the difficulty in handling inequality constraints [1, 8, 9]. Zhu and Xiaong proposed a new approach to study the ORPD using a Modified Interior Point (MIP) method to minimize the system power losses and to penalize any new ORPD utilization while Granade et al. approached a decentralized approach based on Lagragian decomposition method for solving ORPD problem in multi-area power systems however still these classical methods suffer from many drawbacks [10, 11]. Therefore, these numerical-based techniques are not appropriate for taking care of the ORPD issues.

Hence, more modern optimizations methods were proposed in order to improve the drawbacks of the classical methods in finding the ORPD solutions. Aruna and Devaraj has proposed an improved genetic algorithm which permits the control variables to be represented in their natural form have found the result that this method could minimize the losses and suited for solving the mixed integer optimization problem [8]. JAYA algorithm was proved to be well consistent, robust, stable and efficient in determining the optimal location of the control variables for minimizing the active power loss for all the test cases, while satisfying all the constraints simultaneously using ORPD [12]. Khazali and Kalantar have proposed Harmony Search Algorithm (HSA) for determination of the global or near global optimum solution. It has the advantage in decreasing transmission loss, voltage deviation and increasing voltage stability margin compare to simple genetic algorithm (SGA) and particle swarm optimization (PSO) [7]. Mukherjee have proposed chaotic krill herd algorithm (CKHA) to minimize the losses and minimize total voltage deviation. It is a novel metalheuristic search approach which is introduced by Gandomi and Alavi in 2012 based on the simulation of the herding behavior of krill swarms in nature [13]. Besides that, exchange market algorithm (EMA) based on the behavior of shareholders in stock market also used to solve ORPD issues [14]. There are many more algorithms such as Sepiida algorithm (SA) [15], Modified Monkey Optimization (MMO) algorithm [16], Advanced Fireworks Algorithm (AFA) [17], Multi-Verse Optimizer (MVO) [18], Crow Search Algorithm (CSA) [19], Wolf Search Algorithm(WSA) [20], Rapid PSO (RPSO) [21], Gray Wolf Optimizer (GWO) [22,] and many more have been proposed in order to achieve the objectives of the ORPD besides the methods that have been mentioned above.

This paper proposed Evolutionary Programming (EP) algorithm for solving ORPD issues. This method is used to determine the reactive power required to be dispatched by generators in the system and to determine the best grouping of generator that should be operated. The objective function of this tactic is to minimize the transmission loss along the increasing of power loading. EP optimization engine has been established to apply the reactive power dispatch processes. This method was verified on IEEE 30 bus system.

\section{METHODOLOGY}

\subsection{Evolutionary Programming Technique}

Evolutionary Programming (EP) is a stochastic optimization technique which is inspired by the theory of evolution by means of natural selection and was developed by Lawrence J. Fogel in in 1960 for prediction of finite state machine [23, 24]. There are a few types of EP such as classical EP, meta EP, and adaptive EP which every type of EP have different mutation scale. EP finds for ideal solution by developing a population of candidates or parent population over a number of generations. Another population also known as offspring is shaped from the current population (parent) by executing the mutation scale during every generation. The mutation operator delivers afresh solution by perturbing every segment of the present solution by a random amount. The fitness of every candidate solution dictates its strength. The fitness is evaluated from objective function of the optimization problem. In the selection process, every individual from same population will for new generation. The new generation will select the individual that gained the most numbers of successes. The individual that obtained the least numbers of win will be eliminated. These 
processes involved in EP will lead to achieve the global optimal solution. The flowchart of EP is shown in Figure 1.

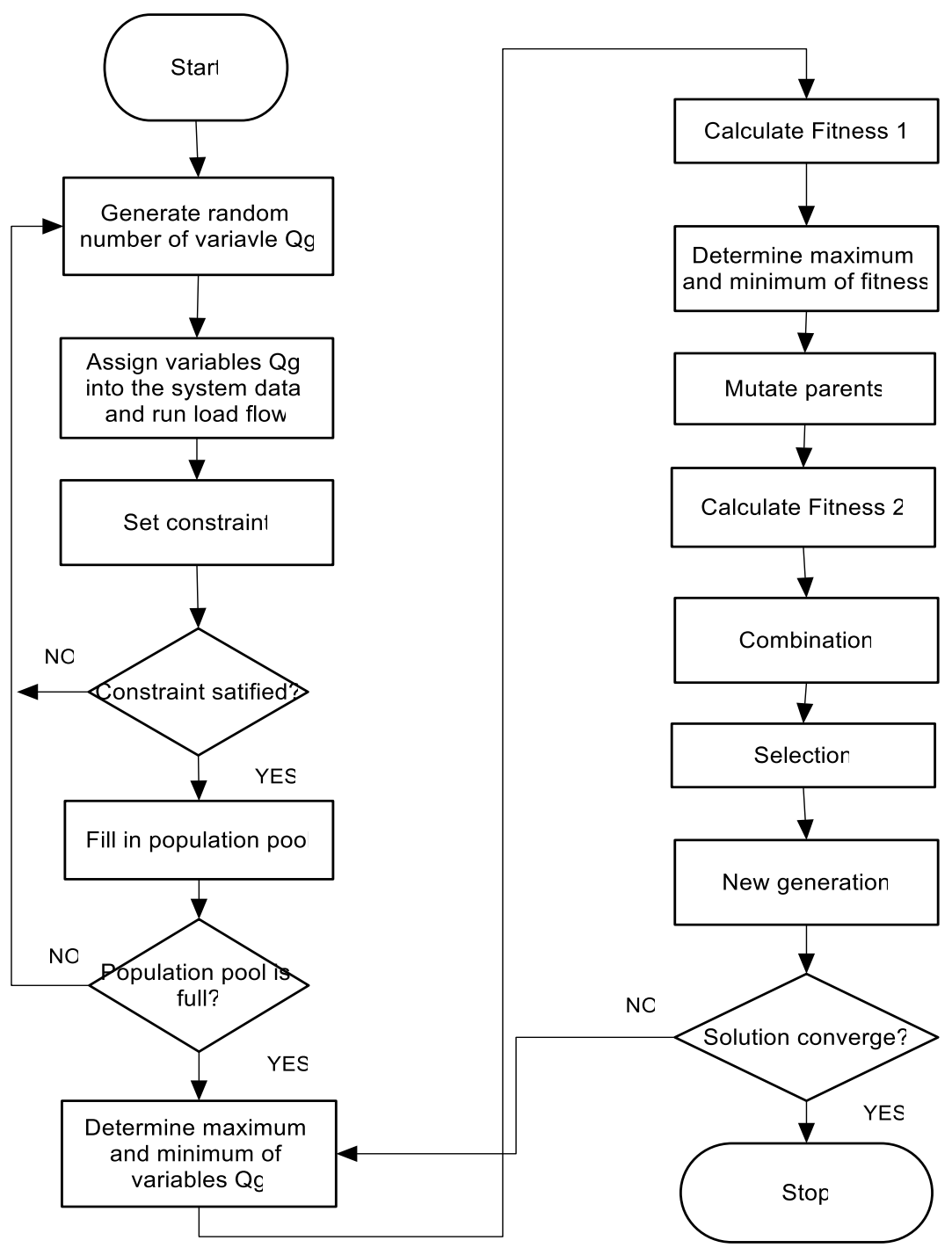

Figure 1. Flowchart of EP operation

\subsubsection{Random Number Generation}

EP operates with a set of population that contains the number of individuals or also known as parent population. At first, the parent population can be produced by generating random number using a uniform distribution number, where:

$$
x i=\left[\lambda_{1}^{i}, \lambda_{2}^{i}, \lambda_{3}^{i}, \ldots, \lambda_{n}^{i}\right]
$$

$i=1,2,3,4,5 \ldots \mathrm{n}$, where $\mathrm{n}$ is the population size with values between the control variable range which is from $\lambda_{\min }$ to $\lambda_{\max }$ in the optimisation process. These random numbers are the new value of reactive power to be dispatched by the generators.

\subsubsection{Assign Load Bus for Test and Run Load Flow}

The number of variables, $x$ from (1) represents the number of generators will be used. The symbol of $\mathrm{x}$ is unfixed. The reactive power on the chosen loads will be represented by parameter in estimating the maximum loading. 


\subsubsection{Set Constraint}

A few constraints are set toward the start to enable EP to create just random numbers that fulfil some predetermined constraints. If constraint is satisfied, the random number will fill the population. If not, new random number will be created.

\subsubsection{Fitness 1 Calculation}

The objective function will be considered and taken as fitness equation. For this study, transmission losses and minimum voltage are objective function which needs to be minimized and maximized within the range by conducting the load flow program. Fitness 1 calculation is the values of the objective function calculated using the first generated population known as parent.

\subsubsection{Mutation}

Mutation is a process to produce the offspring by some random modification of individuals in parent population. This process is implemented based on the (2). The mutation scale is manually adjustable in order to achieve better convergence. Small value of mutation scale causes small search step which leads to fast convergence of EP and vice versa.

$$
x_{i+m j}=x_{i j}+N\left(0, \beta\left(x_{j \max }-x_{j \min }\right)\left(\frac{f_{i}}{f_{\max }}\right)\right)
$$

Where:

$x_{i+m j}=$ mutated parents (offspring)

$x_{i j} \quad=$ parents

$N=$ Gaussian random variable with mean and variance

$\beta=$ mutation scale, 0 to 1

$x_{j \max }=$ maximum random number for every variable

$x_{j \text { min }}=$ minimum random number for every variable

$f_{i} \quad=$ fitness for random number

$f_{\max }=$ maximum fitness

\subsubsection{Fitness 2 calculation} offspring.

Fitness 2 calculation is a recalculation process of objective functions using the mutated parents or

\subsubsection{Combination} population.

In this process, all individuals from parents and offspring will be compiled into new large

\subsubsection{Selection}

This process is used to determine the survivors for next generation where the survivor with better fitness values in the population have big chance of contributing offspring for next generation. Usually, the first half of new large population will be retained as the new individuals while the remaining will be discarded.

\subsubsection{Convergence Test}

In order to decide the stopping point of the generation process, this step needs to be performed. For decision making, the values of maximum fitness and the values of minimum fitness need to be compared and the difference should be less or equal to 0.0001 . The program will stop if the solution converges and if not, Fitness 1 will be calculated again.

\subsection{Optimal Reactive Power Dispatch (ORPD) using EP}

The total lost minimisation was assigned as the objective function and used to implement the ORPD in the system. The variables of this study are the reactive powers that injected on the generator buses for decreasing the total transmission loss of the test system. EP was used to decide the ideal reactive power to be transmitted by the generator bus that used. MATLAB was used in developing the EP program. The ORPD is applied in order to decide the best combination of generator that should utilized as the responsive power compensator backing to the framework and thus improving the power framework security by considering the transmission loss. This can be a decision making guideline that can help the power system operator which is required by service organizations. 
Random numbers that generated during initialization process will be defined as the injected reactive power of the generator buses in the system. The number of generator bus used in the system would influence the number of variables excluding the slack bus. The reactive power at generators $2,5,8,11$, and 13 would be controlled and were represented by five variables by considering the objective; to minimize power loss with load subjected to the system. These five variables are relegated as the reactive load with negative sign showing the reactive power are really infused at the specific buses. A constraint is set as the loss should be less or equal to loss_set. Loss_set here is a loss before the optimization started.

\subsection{Test System}

ORPD using EP was tested on the IEEE 30-bus Reliability Test System for optimising the total loss in the system. There are 24 load buses and 6 generator buses with 41 interconnected lines in this system. Multi cases scenario are created with various combination of five generator buses excluding the slack bus which used as the control variables for the ORPD. Selected generators are indicated with the tick sign.

\section{RESULTS AND ANALYSIS}

The study was verified at an assortment of combinations of generators and at various value of power loading of bus 15 on the IEEE 30-bus RTS to distinguish the outcome to the transmission loss and the minimum voltage. There was one constraint assigned in every grouping of producer before the RPD is executed with EP. The optimization operation is implemented at the various loading of bus 15 from 20VAR until 140MVAR with increment of 20MVAR. The maximum loading of bus 15 is 150MVAR. This loading bus was selected randomly. The result for transmission loss as the objective function is tabulated in the tables as following. The test system parameters values for pre-RDM are set such as mutation scale, 0.0015 and the population with 20 individuals.

\subsection{Multi Cases Generator Combination ORPD}

31 possible grouping for performing the ORPD procedure is applied to 31 possible grouping with five variables were used. The generator $2,5,8,11$, and 13 are utilized as control variables to dispatch the reactive power into the power system in order to observe that the minimum transmission loss is obtained. These tables show the ranking of generator grouping based on the transmission loss. The outcome of transmission loss minimisation when the loading bus 15 is varies between 80Mvar to 140Mvar is shown in Table 1-4.

For 80 Mvar loading bus, as shown in Table 1, the result shows that when only generator 5 works in transmitting the reactive power into the power framework, the obtained transmission loss is the most. The transmission loss is only decreased from $27.8308 \mathrm{MW}$ to $27.7920 \mathrm{MW}$ which is $0.12 \%$ reduction from transmission loss before optimization. At the same moment, the voltage profile is increased from $0.6709 \mathrm{p} . \mathrm{u}$ to 0.6882 p.u. On the other hand, the minimum broadcast loss is gained when generator 2, 8, 11, and 13 are forwarding the reactive power into the power framework. It changes from $27.8308 \mathrm{MW}$ to $24.7412 \mathrm{MW}$ with losses as much as $3.0891 \mathrm{MW}$ and $11.29 \%$ of reduction from transmission loss before optimization while the minimum voltage has increased from 0.6709 p.u to 0.7724 p.u.

Table 2 shows the result of minimised transmission loss when the loading of bus 15 is 100MVAR. From observation, the biggest transmission loss is gained when producer 5 delivers the reactive power into the power system. It changes from $32.6047 \mathrm{MW}$ to $32.3583 \mathrm{MW}$ with a difference of $0.2464 \mathrm{MW}$. It has the highest percentage of transmission loss reduction from before optimization with the value of $14.87 \%$. Simultaneously, the minimum voltage has slightly improved from 0.6422p.u to 0.6556p.u. However, the slightest transmission loss is gained when generator $2,8,11$, and 13 are operating in delivering the reactive power into the power framework. The transmission loss is moderately decreased from $32.6047 \mathrm{MW}$ to $27.7548 \mathrm{MW}$ with a loss of $4.8499 \mathrm{MW}$ with the voltage increased from 0.6422 p.u to 0.7591 p.u. It has $0.76 \%$ of transmission loss reduction from before optimization.

Result that tabulated in Table 3 is about the transmission loss minimisation when the loading bus in 100MVAR. During generator 2, 5, 8, 11, and 13 operating, the obtained transmission loss is the least one while the highest one is during generator 5 operates to transmit the reactive power into the power system. For the least transmission loss, it changes from $39.5358 \mathrm{MW}$ to $31.9114 \mathrm{MW}$ with the voltage increased from 0.6154p.u to 0.7754p.u while for the most transmission loss is from $39.5358 \mathrm{MW}$ to $39.3988 \mathrm{MW}$ with the voltage incremented from 0.6154p.u to 0.6387 p.u after performed optimization. The least transmission loss has the most percentage of the transmission loss reduction from before optimization with the value of $19.28 \%$ while in contrast, $0.35 \%$ for the most transmission loss. 
Table 1. Transmission Loss at bus Loading 80Mvar

\begin{tabular}{|c|c|c|c|c|c|c|c|c|c|c|}
\hline \multicolumn{3}{|c|}{ Trans. Loss (MW) } & \multicolumn{2}{|c|}{ Voltage (p.u) } & \multicolumn{5}{|c|}{ Operating Generator (MVAR) } & \multirow{2}{*}{$\begin{array}{l}\text { Rank } \\
\text { Loss }\end{array}$} \\
\hline Before & After & $\begin{array}{c}\% \text { of } \\
\text { reduction }\end{array}$ & Before & After & Bus 2 & Bus 5 & Bus 8 & Bus 11 & Bus 13 & \\
\hline \multirow[t]{31}{*}{27.8308} & 27.3952 & 1.57 & \multirow[t]{31}{*}{0.6709} & 0.6860 & $v$ & & & & & 29 \\
\hline & 27.7970 & 0.12 & & 0.6882 & & $\sqrt{7}$ & & & & 31 \\
\hline & 26.6001 & 4.42 & & 0.7271 & & & $\sqrt{v}$ & & & 23 \\
\hline & 27.2038 & 2.25 & & 0.6894 & & & & $\sqrt{2}$ & & 28 \\
\hline & 26.9277 & 3.24 & & 0.6972 & & & & & $\sqrt{2}$ & 27 \\
\hline & 27.4257 & 1.46 & & 0.6883 & $\sqrt{1}$ & $\sqrt{1}$ & & & & 30 \\
\hline & 26.4190 & 5.07 & & 0.7294 & $v$ & & $\sqrt{1}$ & & & 18 \\
\hline & 26.6141 & 4.37 & & 0.7159 & $v$ & & & $\sqrt{2}$ & & 24 \\
\hline & 26.2796 & 5.57 & & 0.7232 & 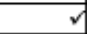 & & & & v & 17 \\
\hline & 25.9453 & 6.77 & & 0.7229 & & & & $\sqrt{2}$ & v & 12 \\
\hline & 25.6221 & 7.94 & & 0.7430 & & & $\sqrt{v}$ & & $\sqrt{7}$ & 7 \\
\hline & 26.5225 & 4.71 & & 0.7114 & & $\sqrt{7}$ & & & 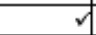 & 21 \\
\hline & 26.5644 & 4.55 & & 0.7282 & & $v$ & $\sqrt{2}$ & & & 22 \\
\hline & 26.8338 & 3.58 & & 0.7039 & & $v$ & & $\sqrt{2}$ & & 26 \\
\hline & 26.0342 & 6.46 & & 0.7359 & & 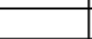 & $\sqrt{2}$ & $\checkmark$ & & 15 \\
\hline & 26.4378 & 5.00 & & 0.7452 & $v$ & $y$ & $\checkmark$ & & & 19 \\
\hline & 26.8141 & 3.65 & & 0.7063 & $v$ & $\sqrt{1}$ & & $\sqrt{2}$ & & 25 \\
\hline & 26.5024 & 4.77 & & 0.7137 & $v$ & 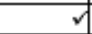 & & & v & 20 \\
\hline & 25.8931 & 6.96 & & 0.7382 & $v$ & & $v$ & $\sqrt{2}$ & & 11 \\
\hline & 25.4739 & 8.47 & & 0.7610 & $\checkmark$ & & 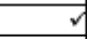 & & 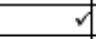 & 5 \\
\hline & 25.6093 & 7.98 & & 0.7411 & $v$ & & & $\sqrt{2}$ & $v$ & 6 \\
\hline & 26.1004 & 6.22 & & 0.7529 & & $v$ & $\checkmark$ & $\sqrt{v}$ & & 16 \\
\hline & 25.6301 & 7.91 & & 0.7598 & & $v$ & $v$ & & $v$ & 8 \\
\hline & 25.8066 & 7.27 & & 0.7387 & & $\checkmark$ & & $\sqrt{2}$ & $v$ & 10 \\
\hline & 25.0040 & 10.16 & & 0.7593 & & & $\sqrt{2}$ & $\sqrt{2}$ & $\checkmark$ & 4 \\
\hline & 25.9917 & 6.61 & & 0.7803 & $v$ & 7 & $\sqrt{7}$ & $\sqrt{2}$ & & 14 \\
\hline & 25.3710 & 6.72 & & 0.7885 & $v$ & $\sqrt{1}$ & $v$ & & $\sqrt{7}$ & 13 \\
\hline & 25.7297 & 7.68 & & 0.7544 & $v$ & 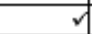 & & $\sqrt{2}$ & 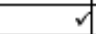 & 9 \\
\hline & 24.7412 & 11.29 & & 0.7724 & $\checkmark$ & & $v$ & $\checkmark$ & 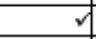 & 1 \\
\hline & 25.0281 & 10.24 & & 0.7758 & & $v$ & $\sqrt{7}$ & $\sqrt{2}$ & $v$ & 3 \\
\hline & 24.8429 & 10.92 & & 0.8024 & $\sqrt{1}$ & $\sqrt{1}$ & $\sqrt{v}$ & 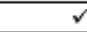 & v & 2 \\
\hline
\end{tabular}

Table 2. Transmission Loss at bus Loading 100Mvar

\begin{tabular}{|c|c|c|c|c|c|c|c|c|c|c|}
\hline \multicolumn{3}{|c|}{ Trans. Loss (MW) } & \multicolumn{2}{|c|}{ Voltage (p.u) } & \multicolumn{5}{|c|}{ Operating Generator (MVAR) } & \multirow{2}{*}{$\begin{array}{l}\text { Rank } \\
\text { Loss }\end{array}$} \\
\hline Before & After & $\begin{array}{c}\% \text { of } \\
\text { reduction }\end{array}$ & Before & After & Bus 2 & Bus 5 & Bus 8 & Bus 11 & Bus 13 & \\
\hline \multirow[t]{31}{*}{39.5358} & 38.9065 & 1.59 & \multirow[t]{31}{*}{0.6154} & 0.6378 & $\sqrt{2}$ & & & & & 30 \\
\hline & 39.3988 & 0.35 & & 0.6387 & & $\sqrt{ }$ & & & & 31 \\
\hline & 37.2130 & 5.88 & & 0.6866 & & & $\sqrt{1}$ & & & 26 \\
\hline & 37.9215 & 4.08 & & 0.6398 & & & & 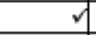 & & 28 \\
\hline & 35.8896 & 9.22 & & 0.6525 & & & & & $y$ & 19 \\
\hline & 38.7163 & 2.07 & & 0.6375 & 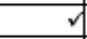 & $\sqrt{2}$ & & & & 29 \\
\hline & 36.1013 & 8.69 & & 0.7144 & $\sqrt{1}$ & & 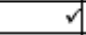 & & & 22 \\
\hline & 37.1409 & 6.06 & & 0.6741 & $\sqrt{1}$ & & & $\sqrt{7}$ & & 24 \\
\hline & 35.2222 & 10.91 & & 0.6854 & $\sqrt{1}$ & & & & 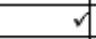 & 15 \\
\hline & 34.1524 & 13.62 & & 0.6818 & & & & v & $v$ & 11 \\
\hline & 33.9952 & 14.01 & & 0.7166 & & & $\sqrt{1}$ & & v & 10 \\
\hline & 35.5561 & 10.07 & & 0.6658 & & $\sqrt{1}$ & & & v & 18 \\
\hline & 36.6048 & 7.41 & & 0.7093 & & $\sqrt{2}$ & $v$ & & & 23 \\
\hline & 37.5595 & 5.00 & & 0.6536 & & $v$ & & v & & 27 \\
\hline & 35.9538 & 9.06 & & 0.7060 & & & 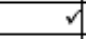 & v & & 20 \\
\hline & 35.9721 & 9.01 & & 0.7312 & 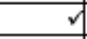 & $v$ & $v$ & 4 & & 21 \\
\hline & 37.1409 & 6.06 & & 0.6741 & $v$ & $\sqrt{ }$ & & v & & 25 \\
\hline & 35.2222 & 10.91 & & 0.6854 & $v$ & $v$ & & - & 1 & 16 \\
\hline & 34.9322 & 11.64 & & 0.7329 & $\checkmark$ & & 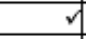 & 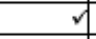 & & 14 \\
\hline & 33.1016 & 16.27 & & 0.7451 & $y$ & & 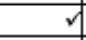 & & v & 6 \\
\hline & 33.6943 & 14.78 & & 0.7006 & $v$ & & & v & v & 8 \\
\hline & 35.3713 & 10.53 & & 0.7109 & & $v$ & $\sqrt{1}$ & v & & 17 \\
\hline & 33.4119 & 15.49 & & 0.7297 & & $\checkmark$ & $y$ & & 1 & 7 \\
\hline & 34.2462 & 13.38 & & 0.6892 & & $v$ & & v & v & 12 \\
\hline & 32.9097 & 16.76 & & 0.7262 & & & v & v & $\sqrt{7}$ & 5 \\
\hline & 34.7528 & 12.10 & & 0.7480 & 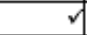 & $\sqrt{ }$ & 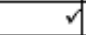 & v & 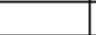 & 13 \\
\hline & 32.8464 & 16.92 & & 0.7575 & $v$ & $v$ & 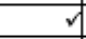 & 1 & v & 4 \\
\hline & 33.8618 & 14.35 & & 0.7041 & $v$ & $v$ & + & $v$ & $v$ & 9 \\
\hline & 32.0685 & 18.89 & & 0.7678 & 1 & & $y$ & v & v & 2 \\
\hline & 32.3380 & 18.21 & & 0.7483 & & $\sqrt{2}$ & 1 & 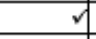 & $y$ & 3 \\
\hline & 31.9114 & 19.28 & & 0.7754 & $\sqrt{2}$ & $\sqrt{1}$ & v & v & v & 1 \\
\hline
\end{tabular}


Table 3. Transmission Loss at Bus Loading 120Mvar

\begin{tabular}{|c|c|c|c|c|c|c|c|c|c|c|}
\hline \multicolumn{3}{|c|}{ Trans. Loss (MW) } & \multicolumn{2}{|c|}{ Voltage (p.u) } & \multicolumn{5}{|c|}{ Operating Generator (MVAR) } & \multirow{2}{*}{$\begin{array}{l}\text { Rank } \\
\text { Loss }\end{array}$} \\
\hline Before & After & $\begin{array}{c}\% \text { of } \\
\text { reduction }\end{array}$ & Before & After & Bus 2 & Bus 5 & Bus 8 & Bus 11 & Bus 13 & \\
\hline \multirow[t]{31}{*}{39.5358} & 38.9065 & 1.59 & \multirow[t]{31}{*}{0.6154} & 0.6378 & $\sqrt{1}$ & & & & & 30 \\
\hline & 39.3988 & 0.35 & & 0.6387 & & 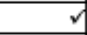 & & & & 31 \\
\hline & 37.2130 & 5.88 & & 0.6866 & & & 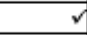 & & & 26 \\
\hline & 37.9215 & 4.08 & & 0.6398 & & & & $\sqrt{1}$ & & 28 \\
\hline & 35.8896 & 9.22 & & 0.6525 & & & & & $\sqrt{1}$ & 19 \\
\hline & 38.7163 & 2.07 & & 0.6375 & 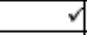 & $\sqrt{2}$ & & & & 29 \\
\hline & 36.1013 & 8.69 & & 0.7144 & $\sqrt{1}$ & & $\sqrt{1}$ & & & 22 \\
\hline & 37.1409 & 6.06 & & 0.6741 & $\sqrt{7}$ & & & $y$ & & 24 \\
\hline & 35.2222 & 10.91 & & 0.6854 & $\sqrt{1}$ & & & & $\sqrt{ }$ & 15 \\
\hline & 34.1524 & 13.62 & & 0.6818 & & & & v & $\sqrt{1}$ & 11 \\
\hline & 33.9952 & 14.01 & & 0.7166 & & & $\sqrt{2}$ & & $\sqrt{1}$ & 10 \\
\hline & 35.5561 & 10.07 & & 0.6658 & & $\sqrt{1}$ & & & $v$ & 18 \\
\hline & 36.6048 & 7.41 & & 0.7093 & & $v$ & $\sqrt{2}$ & & & 23 \\
\hline & 37.5595 & 5.00 & & 0.6536 & & $v$ & & $\sqrt{1}$ & & 27 \\
\hline & 35.9538 & 9.06 & & 0.7060 & & & $\sqrt{2}$ & v & & 20 \\
\hline & 35.9721 & 9.01 & & 0.7312 & 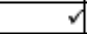 & $\sqrt{2}$ & 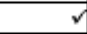 & & & 21 \\
\hline & 37.1409 & 6.06 & & 0.6741 & 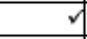 & $\checkmark$ & & v & & 25 \\
\hline & 35.2222 & 10.91 & & 0.6854 & $v$ & $\checkmark$ & & $\Rightarrow$ & $v$ & 16 \\
\hline & 34.9322 & 11.64 & & 0.7329 & $v$ & & $\checkmark$ & v & & 14 \\
\hline & 33.1016 & 16.27 & & 0.7451 & $v$ & & $\checkmark$ & & $\sqrt{1}$ & 6 \\
\hline & 33.6943 & 14.78 & & 0.7006 & $v$ & & & 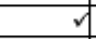 & $\checkmark$ & 8 \\
\hline & 35.3713 & 10.53 & & 0.7109 & & 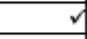 & $\checkmark$ & v & & 17 \\
\hline & 33.4119 & 15.49 & & 0.7297 & & $\checkmark$ & $\checkmark$ & + & $v$ & 7 \\
\hline & 34.2462 & 13.38 & & 0.6892 & & $v$ & & v & $v$ & 12 \\
\hline & 32.9097 & 16.76 & & 0.7262 & & & $\sqrt{2}$ & v & $v$ & 5 \\
\hline & 34.7528 & 12.10 & & 0.7480 & $v$ & $\checkmark$ & $\sqrt{2}$ & v & & 13 \\
\hline & 32.8464 & 16.92 & & 0.7575 & $\checkmark$ & $\checkmark$ & $\sqrt{2}$ & + & $\checkmark$ & 4 \\
\hline & 33.8618 & 14.35 & & 0.7041 & $v$ & $v$ & & v & $\checkmark$ & 9 \\
\hline & 32.0685 & 18.89 & & 0.7678 & 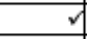 & & $\sqrt{2}$ & v & $\checkmark$ & 2 \\
\hline & 32.3380 & 18.21 & & 0.7483 & & $v$ & $\checkmark$ & 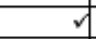 & $v$ & 3 \\
\hline & 31.9114 & 19.28 & & 0.7754 & $v$ & $v$ & $v$ & v & $v$ & 1 \\
\hline
\end{tabular}

Table 4. Transmission Loss at Bus Loading 140Mvar

\begin{tabular}{|c|c|c|c|c|c|c|c|c|c|c|}
\hline \multicolumn{3}{|c|}{ Trans. Loss (MW) } & \multicolumn{2}{|c|}{ Voltage (p.u) } & \multicolumn{5}{|c|}{ Operating Generator (MVAR) } & \multirow{2}{*}{$\begin{array}{l}\text { Rank } \\
\text { Loss }\end{array}$} \\
\hline Before & After & $\begin{array}{c}\% \text { of } \\
\text { reduction }\end{array}$ & Before & After & Bus 2 & Bus 5 & Bus 8 & Bus 11 & Bus 13 & \\
\hline \multirow[t]{31}{*}{53.2168} & 52.3333 & 1.66 & \multirow[t]{31}{*}{0.5686} & 0.5821 & $\sqrt{1}$ & & & & & 31 \\
\hline & 51.2021 & 3.79 & & 0.6114 & & $\sqrt{2}$ & & & & 30 \\
\hline & 47.2477 & 11.22 & & 0.6726 & & & $\sqrt{2}$ & & & 24 \\
\hline & 49.3656 & 7.24 & & 0.6015 & & & & $\sqrt{1}$ & & 28 \\
\hline & 44.3256 & 16.71 & & 0.6220 & & & & & $\sqrt{2}$ & 19 \\
\hline & 51.1300 & 3.91 & & 0.6176 & $\sqrt{ }$ & $\sqrt{2}$ & & & & 29 \\
\hline & 45.6215 & 14.27 & & 0.6831 & $\sqrt{2}$ & & $\sqrt{1}$ & & & 22 \\
\hline & 47.5863 & 10.58 & & 0.6296 & $\sqrt{2}$ & & & $\sqrt{2}$ & & 26 \\
\hline & 43.1096 & 18.99 & & 0.6474 & $\sqrt{2}$ & & & $\rightarrow$ & $\sqrt{1}$ & 14 \\
\hline & 41.8656 & 21.33 & & 0.6496 & & & & $\sqrt{1}$ & $\sqrt{1}$ & 12 \\
\hline & 41.0631 & 22.84 & & 0.7135 & & & $\sqrt{7}$ & & $\sqrt{1}$ & 16 \\
\hline & 44.0668 & 17.19 & & 0.6309 & & $\sqrt{2}$ & & & $\sqrt{2}$ & 18 \\
\hline & 46.2640 & 13.07 & & 0.6744 & & $\sqrt{ }$ & $\sqrt{1}$ & & & 23 \\
\hline & 48.6058 & 8.66 & & 0.6271 & & $\sqrt{2}$ & & $\sqrt{2}$ & & 27 \\
\hline & 44.9681 & 15.5 & & 0.6925 & & & $v$ & $v$ & & 20 \\
\hline & 44.9781 & 15.48 & & 0.6904 & $\sqrt{2}$ & $\checkmark$ & $\sqrt{1}$ & 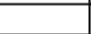 & & 21 \\
\hline & 47.4501 & 10.84 & & 0.6547 & $v$ & $\checkmark$ & & $v$ & & 25 \\
\hline & 43.2260 & 18.77 & & 0.6692 & $v$ & $\checkmark$ & & 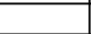 & $v$ & 15 \\
\hline & 43.5513 & 18.16 & & 0.7069 & $\sqrt{1}$ & & $\sqrt{1}$ & $\checkmark$ & & 16 \\
\hline & 39.8641 & 25.09 & & 0.7309 & $\sqrt{1}$ & & $\sqrt{1}$ & & $v$ & 6 \\
\hline & 41.0093 & 22.94 & & 0.6663 & $v$ & & & $v$ & $v$ & 9 \\
\hline & 43.9541 & 17.41 & & 0.7026 & & $\sqrt{2}$ & $v$ & $\sqrt{1}$ & & 17 \\
\hline & 40.2053 & 24.45 & & 0.7293 & & $\checkmark$ & $v$ & 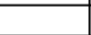 & $v$ & 7 \\
\hline & 41.5501 & 21.92 & & 0.6646 & & $\checkmark$ & & $\sqrt{1}$ & $v$ & 11 \\
\hline & 39.3868 & 25.99 & & 0.7239 & & & $\sqrt{1}$ & $\sqrt{1}$ & $\sqrt{1}$ & 5 \\
\hline & 42.9159 & 19.36 & & 0.7108 & $\sqrt{2}$ & $\sqrt{2}$ & 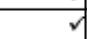 & $\sqrt{1}$ & & 13 \\
\hline & 39.3116 & 26.13 & & 0.7391 & $\checkmark$ & $\checkmark$ & $\sqrt{1}$ & $\longrightarrow$ & $v$ & 4 \\
\hline & 40.6050 & 23.70 & & 0.6834 & 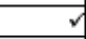 & $\checkmark$ & & 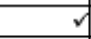 & $v$ & 8 \\
\hline & 38.3461 & 27.94 & & 0.7492 & $v$ & & $v$ & $v$ & $v$ & 2 \\
\hline & 38.8350 & 27.02 & & 0.7500 & & $\checkmark$ & $v$ & $v$ & $v$ & 3 \\
\hline & 38.0275 & 28.54 & & 0.7501 & $\sqrt{1}$ & $\checkmark$ & $\sqrt{1}$ & $\sqrt{1}$ & 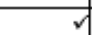 & 1 \\
\hline
\end{tabular}


Table 4 shows the result of transmission loss minimisation when the loading of bus 15 is 140MVAR. The highest percentage of reduction from transmission loss before optimization is when the generator $2,5,8,11$, and 13 operate in sending the responsive power into the power framework. The transmission loss is observed decreasing from $53.2168 \mathrm{MW}$ to $38.0275 \mathrm{MW}$ with the losses as much as 15.1893MW. At meantime, the voltage profile incremented from 0.5686p.u to 0.7501p.u. On the other hand, the lowest percentage of reduction from transmission loss before optimization is when generator 2 does its work to dispatch the reactive power into the power system where the transmission has most loss. It is seen that the transmission loss is decremented from $53.2168 \mathrm{MW}$ to $52.3333 \mathrm{MW}$ with the least loss. While its voltage slightly increased from 0.5686 p.u to 0.5821 p.u.

\subsection{The Best 3 of Selected Operating Generator Combination}

The percentage of transmission loss is obtained by using the following equation:

transmission loss before - transmission loss after

transmission loss before

Table 5 shows the best three combination of operating generator in minimising the transmission loss at different loading value of bus 15 . These three combinations are selected from 31 possible combinations of generator 2, 5, 8, 11, and 13. From this table, it is observed that when the loading is increasing, the percentage of transmission loss reduction by using RPD is also increasing. It also shows that it is not necessary to operate all generators for minimising the transmission loss. For example, only three generators are used to achieve the better minimised transmission loss at loading of 20MVAR. It showed that by determining the combination of which generators is important in giving the better result for achieving the objective.

Table 5. The Best Three Combination of Operating Generators

\begin{tabular}{|c|c|c|c|c|c|c|}
\hline \multirow{2}{*}{$\begin{array}{l}\text { Loading } \\
\text { at bus } 15 \\
\text { (MVAR) }\end{array}$} & \multirow{2}{*}{$\begin{array}{l}\text { Percentage } \\
\text { of Trans. } \\
\text { Loss }(\%)\end{array}$} & \multicolumn{5}{|c|}{ Optimal reactive Power Dispatch (MVAR) } \\
\hline & & Bus 2 & Bus 5 & Bus 8 & Bus 11 & Bus 13 \\
\hline \multirow[t]{3}{*}{20} & 5.14 & 107.4425 & 85.6655 & 80.7440 & 164.3310 & 210.4811 \\
\hline & 4.81 & 97.5549 & & 104.9814 & 121.8530 & \\
\hline & 4.47 & 123.0677 & & 99.4078 & 246.5101 & 194.5321 \\
\hline \multirow[t]{3}{*}{40} & 6.23 & 107.4425 & 85.6655 & 80.7440 & 164.3310 & 210.4811 \\
\hline & 6.16 & 63.3684 & & 133.4972 & 187.3545 & 167.7953 \\
\hline & 5.76 & & & 99.4078 & 246.5101 & 194.5321 \\
\hline \multirow[t]{3}{*}{60} & 8.96 & 107.4425 & 85.6655 & 80.7440 & 164.3310 & 210.4811 \\
\hline & 8.69 & 145.5464 & & 97.5549 & 104.9814 & 121.8530 \\
\hline & 8.38 & & & 99.4078 & 246.5101 & 194.5321 \\
\hline \multirow[t]{3}{*}{80} & 11.29 & 123.0677 & & 99.4078 & 246.5101 & 194.5321 \\
\hline & 10.92 & 105.4164 & 232.7635 & 155.9495 & 142.8892 & 238.1960 \\
\hline & 10.24 & & 133.4972 & 187.3545 & 167.7953 & 63.3684 \\
\hline \multirow[t]{3}{*}{100} & 14.87 & 126.8284 & & 105.4164 & 232.7635 & 155.9495 \\
\hline & 14.82 & 120.2030 & 152.6547 & 168.2227 & 219.1963 & 132.4162 \\
\hline & 13.99 & & & 63.3684 & 133.4972 & 187.3545 \\
\hline \multirow[t]{3}{*}{120} & 19.28 & 105.4164 & 232.7635 & 155.9495 & 142.8892 & 238.1960 \\
\hline & 18.89 & 115.6468 & & 176.5277 & 201.2821 & 248.2075 \\
\hline & 18.21 & & 83.3014 & 147.3035 & 229.5313 & 231.8416 \\
\hline \multirow[t]{3}{*}{140} & 28.54 & 105.4164 & 232.7635 & 155.9495 & 142.8892 & 238.1960 \\
\hline & 27.94 & 115.6468 & & 176.5277 & 201.2821 & 248.2075 \\
\hline & 27.02 & & 115.6468 & 176.5277 & 201.2821 & 248.2075 \\
\hline
\end{tabular}

\section{CONCLUSION}

ORPD for transmission loss minimisation using EP as the optimisation approach was presented. Transmission loss is decided to be the fitness function and must be minimised along the increment of power loading at bus 15 . The result obtained showed the objective to minimise the transmission loss is achieved. At the same time, the best three combination of operating generators was determined based on ranking of the transmission loss. This result from the multi cases combination of operating generators can be used as a guide in helping the system operator in scheduling the generators and can avoid all generators to operate at one time. Increment of the loading bus showed the increasing of transmission loss. However, this issue can be overcome by ORPD using EP. In the conclusion, ORPD using EP is very efficient and can give a very good performance in minimising the transmission loss. 


\section{ACKNOWLEDGEMENTS}

The author would like to acknowledge the Institute of Research Management and Innovation (IRMI), UiTM Shah Alam, Selangor, Malaysia for the financial support of this research. This research is supported by IRMI under BESTARI Grant Scheme with project code: 600-IRMI/PERDANA 5/3 BESTARI (095/2018).

\section{REFERENCES}

[1] M. Varadarajan and K. S. Swarup, "Differential Evolution Algorithm for Optimal Reactive Power Dispatch," Appl. Soft Comput. 8, pp. 1549-1561, 2007.

[2] S. Azma and S. Mustaffa, "Load Management for Voltage Stability Control in Multi-Area Power System", 2016 6th IEEE International Conference on Control System, Computing and Engineering (ICCSCE), 2016.

[3] M. Ghasemi and A. R. Roosta, "Imperialist Competitive Algorithm for Optimal Reactive Power," vol. 2, no. 2, pp. 13-20, 2013.

[4] A. Ghasemi, K. Valipour, and A. Tohidi, "Multi Objective Optimal Reactive Power Dispatch Using A New Multi Objective Strategy," Int. J. Electr. Power Energy Syst., vol. 57, pp. 318-334, 2014.

[5] S. A. Taher and M. Pakdel, "Solution of Multi-Objective Optimal Reactive Power Dispatch Using Pareto Optimality Particle Swarm Optimization Method", Journal of AI and Data Mining, vol. 2, pp. 39-52, 2014.

[6] A. Rajan and T. Malakar, "Optimal Reactive Power Dispatch Using Hybrid Nelder-Mead Simplex Based Firefly Algorithm," Int. J. Electr. Power Energy Syst., vol. 66, pp. 9-24, 2015.

[7] A. H. Khazali and M. Kalantar, "Optimal Reactive Power Dispatch Based on Harmony Search Algorithm," Int. J. Electr. Power Energy Syst., vol. 33, no. 3, pp. 684-692, 2011.

[8] P. A. Jeyanthy and D. Devaraj, "Optimal Reactive Power Dispatch for Voltage Stability Enhancement Using Real Coded Genetic Algorithm,” Int. J. Comput. Electr. Eng., vol. 2, no. 4, pp. 734-740, 2010.

[9] D. Lenin, "Vortex Optimization Algorithm for Solving Optimal Power Flow," Int. J. Res. Granthaalayah, vol. 6, pp. 266-276, 2018.

[10] B. Mandal and P. Kumar Roy, "Multi-Objective Optimal Power Flow Using Quasi-Oppositional Teaching Learning Based Optimization,” Appl. Soft Comput. J., vol. 21, pp. 590-606, 2014.

[11] M. Mehdinejad, B. Mohammadi-Ivatloo, R. Dadashzadeh-Bonab, and K. Zare, "Solution of Optimal Reactive Power Dispatch of Power Systems Using Hybrid Particle Swarm Optimization and Imperialist Competitive Algorithms," Int. J. Electr. Power Energy Syst., vol. 83, pp. 104-116, 2016.

[12] R. Roy and T. Das, "Optimal Reactive Power Dispatch using JAYA Algorithm," 2018 Emerg. Trends Electron. Devices Comput. Tech., no. 7, pp. 1-6, 2018.

[13] A. Mukherjee and V. Mukherjee, "Chaotic Krill Herd Algorithm for Optimal Reactive Power Dispatch Considering FACTS Devices,” Appl. Soft Comput. J., vol. 44, pp. 163-190, 2016.

[14] A. Rajan and T. Malakar, "Exchange Market Algorithm Based Optimum Reactive Power Dispatch", Appl. Soft Comput. J., vol. 43, pp. 320-336, 2016.

[15] K. Lenin, "Sepiida Algorithm for Solving Optimal Reactive Power Problem", International Robotics \& Automation Journal, vol. 4, no. 4, pp. 289-294, 2018.

[16] K. Lenin, B. R. Reddy, and M. Surya Kalavathi, "Modified Monkey Optimization Algorithm for Solving Optimal Reactive Power Dispatch Problem," Indonesian Journal of Electrical Engineering and Informatics (IJEEI), vol. 3, no. 2, pp. 55 62, 2015.

[17] K. Lenin, "Advanced Fireworks Algorithm for Solving Optimal Reactive Power Dispatch Problem," Int. J. Comput. Sci. Eng., vol. 6, no. 6, pp. 625-631, 2018.

[18] M. H. Sulaiman, Z. Mustaffa, M. R. Mohamed, and O. Aliman, "An Application of Multi-Verse Optimizer for Optimal Reactive Power Dispatch Problems,” Int. J. Simul. Syst. Sci. Technol., vol. 17, no. 41, pp. 1-5, 2017.

[19] L. M and R. K. A, "Optimal Reactive Power Dispatch using Crow Search Algorithm”, Int. J. Electr. Comput. Eng., vol. 8, no. 3, p. 1423, 2018.

[20] K. Lenin, B. Ravindhranath Reddy, M. Surya Kalavathi, "Wolf Search Algorithm for Solving Optimal Reactive Power Dispatch Problem", Indonesian Journal of Electrical Engineering and Informatics (IJEEI), Vol. 3, No. 1, pp. 7 15, March 2015.

[21] K. Lenin, B. Ravindhranath Reddy, M. Surya Kalavathi, "Rapid Particle Swarm Optimization Algorithm for Solving Optimal Reactive Power Dispatch Problem", Indonesian Journal of Electrical Engineering and Informatics (IJEEI), Vol. 5, No. 2, pp. 99 107, June 2017.

[22] M. H. Sulaiman, Z. Mustaffa, M. R. Mohamed, and O. Aliman, "Using The Gray Wolf Optimizer for Solving Optimal Reactive Power Dispatch Problem,” Appl. Soft Comput. J., vol. 32, pp. 286-292, 2015.

[23] I. Musirin, T. Khawa, and A. Rahman, "Evolutionary Programming Optimization Technique for Solving Reactive Power Planning in Power System", Proceedings of the 6th WSEAS Int. Conf. on Evolutionary Computing, Lisbon, Portugal, pp. 239-244, 2005.

[24] D. B. Fogel, L. J. Fogel, and J. W. Atmar, "Meta-Evolutionary Programming", Twenty-Fifth Asilomar Conference on Signals, Systems \& Computers, California, pp. 540-545, 1991. 